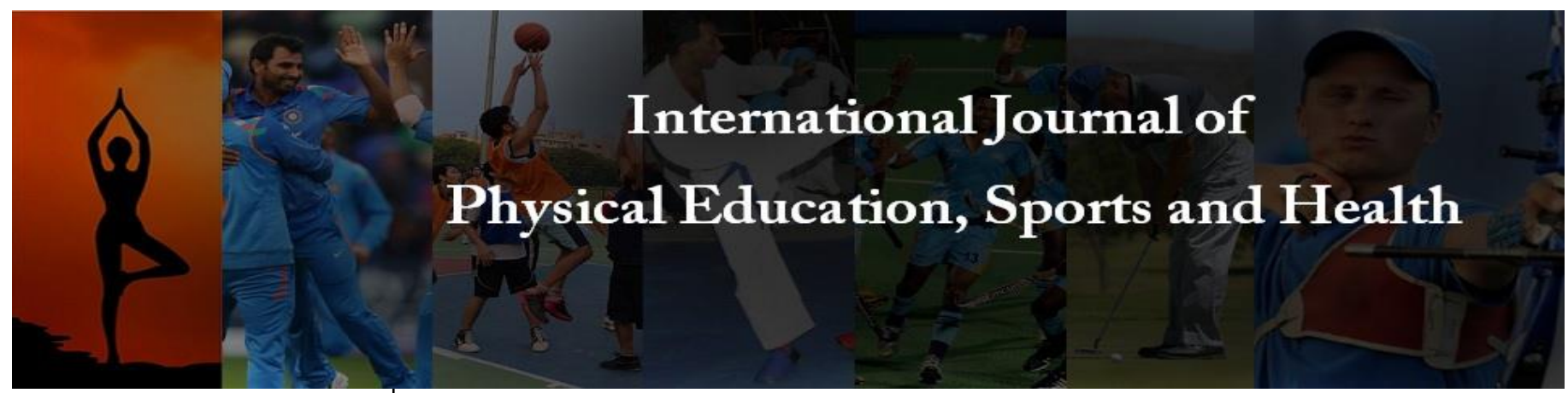

P-ISSN: 2394-1685

E-ISSN: 2394-1693

Impact Factor (ISRA): 5.38

IJPESH 2018; 5(5): 113-116

(C) 2018 IJPESH

www.kheljournal.com

Received: 12-07-2018

Accepted: 26-08-2018

Dr. Paramjit Kaur

Head, Department of

Psychology, G.H.G. Khalsa

College, Gurusar Sadhar

Ludhiana, Punjab, India
Corresponding Author: Dr. Paramjit Kaur Head, Department of Psychology, G.H.G. Khalsa College, Gurusar Sadhar Ludhiana, Punjab, India

\section{Influence of physical activity on behavioral distinctiveness among young children}

\section{Dr. Paramjit Kaur}

DOI: https://doi.org/10.22271/kheljournal.2018.v5.i5b.1999

\section{Abstract}

The present paper intends to illuminate some of the very sensitive issues of the present day scenario of children who are not interested in physical activity but rather prefer to stay indoors in order to play games on mobiles, laptops or watch televisions. The basic problem is sedentary lifestyle which creates havoc with the health of growing children and as result restricts their psychological and social development. Several critical elements that are necessary to develop and maintain a healthy mind and body have been put forth. The paper suggests that sports and physical activity should be encouraged. It is essential for parents to recognize that sports in the form of physical activity is important in structuring the psyche and personality of children who are the future of a nation. An attempt has been made to show that when a child perfects a skill he has been working at he learns to push himself self in a healthy manner. Instead of taking short cuts, the child learns to take the baseline skill, practices it, and achieves the level of success he is striving for. This cycle is one that can later help in taking their careers and to help manage stress and all the things life can throw at them.

Keywords: Life-style, sedentary, children, diseases, health

\section{Introduction}

According to the World Health Organization, a sedentary lifestyle could very well be among the ten leading causes of death and disability in the world. It has been found that the average kid in the 8-18 years age group, is spending an alarming seven hours in front of the screen (television, mobile, laptop) every day. It is estimated that 20 to 25 percent of children are either overweight or obese - this is an alarming health trend. The problem is that overweight children are more likely to turn into overweight adults who are often inactive and face a huge range of health problems. This is also known as the sedentary lifestyle.

Sedentary lifestyle: A sedentary lifestyle or behaviour is defined as little or no physical activity in the daily routine. Most of the time is spent either sitting or lying down while engaging in an activity like reading, watching TV, playing games on screen or just relaxing. A sedentary lifestyle doubles the risk of cardiovascular diseases, diabetes and obesity. It also increases the risks of colon cancer, high blood pressure, osteoporosis, lipid disorders, depression and anxiety. According to a study, 'Physical activity in childhood may be the key to optimizing lifespan skeletal health, published by the National Center for Biotechnology Information, in the year 2013, an hour of outdoor play or engaging in a physical activity every day is extremely important for children. This may or may not be all at one go, but can be beneficial even when done in chunks of 15-20 minutes are beneficial in many ways. It helps them burn energy, tone the muscles and helps stimulate the brain. The human body is meant to move. So, any lack of physical activity deteriorates and weakens the body, sags the muscles and stiffens the joints and causes pain.

Ill effects of sedentary lifestyle: Muscle mass reduction: A lack of physical activity reduces the muscle mass and makes simple activities painful. It may also increase the risk of developing physical and psychological pain such as headaches, musculoskeletal and abdominal pain. 
Detrimental behavior: A sedentary lifestyle in children can lead to a domino effect of bad habits and detrimental behaviour in future. Children, who sit for longer also tend snack often especially the unhealthy stuff. This is directly related to weight gain and it increases the risk of developing chronic illnesses like obesity, diabetes, hypertension etc. These are carried through to adulthood and causes other related problems as well.

Depression and mood swings: An inactive lifestyle is linked to a 25 per cent higher chance of feeling low and depressed, and displaying mood swings etc. The body releases endorphins and serotonin when active, which leads to the feelgood factor. This in turn reduces the risk of depression and helps reduce anxiety too.

Sleep disturbances: Children who don't get enough exercise tend to snap or get irritated easily. It is also observed that just sitting reduces the brain activity and functioning in children. A sedentary lifestyle can affect the sleep cycle of your child, as he needs to feel tired before the end of the day to get sound sleep. All day sitting and lying makes the body lazy and leads to lower levels of sleep, in turn, feeling more tired and other related issues. Sedentary behaviour may contribute to negative mood by enhancing inflammatory responses to stress leading to an upregulation signalling pathway and enhanced vulnerability to mood disturbances.

Physical activities and Sports: Being active not only keeps children and young people fit and healthy, but provides all kinds of social, emotional and intellectual benefits. Physical activities such as games or sports helps much more psychologically than in the physical aspects. It builds character, improves cognition, leadership skills, goal setting and much more. Children are encouraged to play sports because being physically active is healthy for the mind and body. People who play sports also learn character and behaviour traits that help fill out their personalities. Sports and games play an important role in the development of human personality. All sports and games certainly benefit both the mind and body and create discipline, team building, confidence and physical fitness. Getting children involved in sport will help them get more active and also develop a healthier personality. Physically players develop their strength, speed, skill, stamina and flexibility but it also increases self-esteem, builds social skills and leadership, increases resilience and inculcates values. When we are under stress from personal or work problems exercise through playing sports helps release pressure and tension in a healthy and controlled way.

Children who play sports get more chance of meeting and interacting with people of similar interests and make new friends, this boosts their confidence. Children playing together as a team, share and celebrate together. This has a positive effect on a child's psychology and behaviour. Players then are less likely to become selfish when they grow up; they are caring and readily to work as a team and get along better with others. The other areas where sports assists the developing children are as follows:

Increased Self Esteem: It takes physical, mental and emotional endurance to compete and children learn motivation, determination and the long term benefits of training and working toward a goal. The feeling of accomplishment as they work to build their playing skills improves self-esteem, a personality trait that is important in taking on other challenges in life.

Improved Social Skills: Playing a team sports help players bond with each other. It requires cooperating with others, learning to play fair and having fun with others while working toward a common goal. Players develop a healthy sense competition with team mates. This gives children better skills to interact with others at school and home.

Leadership Abilities: Even as simple as getting to training on time and with the correct equipment is a start to leadership skills. Playing sport teaches players to take on leadership roles such as handling conflict, developing game strategies and encouraging team members.

Resilience: Learning to cope with the emotional highs and lows of life in a healthy manner is a valuable personality trait for children and adults. Playing sport gives people the experiences of joy and excitement after a win and grief and frustration after a loss. Sport gives children an organised and structured environment where coaches and team members can provide encouragement and help build resilience.

\section{Academic benefits}

Increased capacity for learning and productivity: Active children are generally more motivated and better organised than children who are inactive, and physical activity has direct links to improved learning outcomes

Positive school environment - active students are generally less aggressive and experience fewer discipline problems

Builds Stamina: A sound mind rests in a sound body. Playing sports will not only give your child the necessary physical exercise to develop her stamina, but it will also make her less sluggish and become more active. Her ability to study for long hours will also increase.

Helps focus: Excelling in any sport requires single-minded dedication. Achieving any target such as scoring a goal, hitting the ball or shooting an arrow requires concentration. Your child will learn how to devote all his time and thoughts to mastering new techniques, to be better in the game. Once he learns to focus, he will be able to give all his attention to his assignments and concentrate on studying.

Instills Discipline: To be successful in any sport, your child has to develop a rigorous routine. This will help her appreciate the importance of a disciplined lifestyle. She will learn to efficiently divide her time between different tasks. She will also understand the value of maintaining a routine and follow the same principle while pursuing her academics.

Teaches hard work: 'Practice, practice and more practice' that's the mantra any sports teacher will teach a child. He will learn that success comes with hard work and will learn to apply the same rule to his academics as well. When he associates effort with results, he will be able to work toward bigger goals in his academic work.

\section{Emotional benefits}

Physical activity has been shown to stimulate chemicals in the brain that make you feel better. So playing sport regularly improves children's overall emotional wellbeing.

Boosts self-esteem: Research shows there's a link between playing sport and self-esteem in children. The support of the 
team, a kind word from a coach, or achieving their personal best will help children to feel better about themselves By being a part of competitive sports or just by training for a game, a child will develop a healthy self-esteem. Winning matches and the appreciation and adulation that follow, act as great morale boosters.

Builds resilience: When children start participating in matches and playing competitive sports, They are bound to face failures along with success. These instances will help them see failure and success as two sides of the same coin. They will learn to bounce after suffering losses. This will make them mentally and emotionally resilient which in return will help help them face various setbacks in life.

Boosts achievement orientation: Sports infuses a spirit of healthy competition in children as they strive to be the best in their game by sharpening their skills. Children also learn not to settle for anything but the best and will work hard towards achieving greater success by knowing his strengths and working on his limitations. This will teach them never to settle for the second-best.

Develops a spirit of sportsmanship: As sportspersons, children will come across others with the same skill set. At times they may face defeat at the hands of highly-skilled opponents. This teaches them to aspire to be the best and respect those better and more talented than them. This attitude helps in long term success.

Better coping skills: Development from sport goes beyond learning new physical skills. Sport helps children develop better ways to cope with the highs and lows of life. When they're playing sport, children learn to lose. Being a good loser takes maturity and practice. Losing teaches children to bounce back from disappointment, cope with unpleasant experiences and is an important part of becoming resilient. Playing sports helps children learn to control their emotions and channel negative feelings in a positive way. It also helps children to develop patience and understand that it can take a lot of practice to improve both their physical and psychosocial skills.

Teaches team spirit: Playing in a team helps children to develop many of the social skills they will need for life. It teaches them to cooperate, to be less selfish, and to listen to other children along with a sense of belonging. It helps them make new friends and builds their social circle outside school. An important part of playing in a team is accepting discipline. Playing sport means children are expected to follow rules, accept decisions and understand that they could be penalised for bad behaviour. It will teach them to take directions from the coach, referees and other adults. Sport will also teach them all about team work. Playing in a team and trying to win for the team will teach the child to be selfless. They start putting the interests of the team before their own and will do what is best collectively for the group rather than for their own self individually.

Team Building: Children learn how to get along with their peers and interact positively through sport. It builds team spirit whether they win or lose. Simple things like shaking hands is a gesture of appreciation for both teams.

Enhanced leadership skills: One of the best life skills that playing sports teaches children is leadership. A child need not necessarily be the captain of his or her team or hold a leadership position to imbibe this quality. Just being part of a team and taking the game seriously, is enough to bring in her a sense of responsibility and build the courage to take initiatives and decisions confidently, while guiding others.

Builds strategic skills: All competitive sports involve building a strategy at the team level or the individual level. Studying the opponents technique and coming up with ways to counter it, needs immense analytical powers. Playing in matches also require players to think quickly on their feet and come up with new strategies. This way, the child will learn how to strategise and use this skill in other areas of their life as well.

Teaches patience: There are times when a childs sporting career when he or she will have to wait long before tasting success. They may go through failures which in return make them learn the importance of being patient, even when things do not go easy. It teaches them to keep trying until they win.

Improved mental health: Participation in sports and games also improves concentration skills and ability to manage anxiety and stress

A reduction in anti-social behaviour: Active children who are engaged in sports are less likely to smoke, use illicit drugs or be involved in criminal activity.

Role of parents: It is important for parents to set an example and behave as positive role models for children to follow them. Planning regular family trips to places close to nature may lead to activities like hiking, swimming, and climbing. Enrolling the child in a sport that he/she enjoys is also a great way to get the body moving and learn many more things simultaneously. To keep your child interested and enjoying sport, make it a positive experience for them. Focus on having fun, having a go and being active, rather than winning or losing. Children can be helped in developing a positive sporting attitude by praising the team's or other children's efforts, even if they don't win. Parents can explain it to their children that how important that how important it is to try and do their best.

\section{Conclusion}

It can be concluded that leading an active lifestyle is good for children and adults or people of all the ages. Even if children are motivated to participate in regular moderate physical activity, they can enjoy numerous health and social benefits. These children who are the future of the nation should become healthy adults as well. It is estimated that 20 to 25 percent of children are either overweight or obese, this is an alarming health trend. The problem is that overweight children are more likely to turn into overweight adults who are often inactive and face a huge range of health problems. Sports and physical activity in return reduces risk of heart disease and stroke, high blood pressure, prevention of some cancers, reduced risk of becoming overweight, reduced risk of developing diabetes and prevention and treatment of noninsulin dependent diabetes. It gives better bone and muscle development and prevention of osteoporosis, improved muscle flexibility, strength and endurance. Being active not only keeps children and young people fit and healthy, but provides all kinds of social, emotional and intellectual benefits. 


\section{References}

1. Coe DP, Pivarnik JM, Womack CJ, Reeves MJ, Malina RM. Effects of physical education and activity levels on academic achievement in children. Medicine \& Science in Sports \& Exercise 2006;38(8):15151520.

2. Davis CL, Tomporowski PD, Boyle CA, Waller JL, Miller PH, Naglieri JA. Effects of aerobic exercise on overweight children's cognitive functioning: A randomized controlled trial. Research Quarterly for Exercise and Sport, 2007, 78(5).

3. Eveland-Sayers BM, Farley RS, Fuller DK, Morgan DW, Caputo JL. Physical fitness and academic achievement in elementary school. Journal of Physical Activity and Health, 2009, 6(1).

4. Sigfusdottir DI, Kristjansson AL, Allegrante JP. Health behaviour and academic achievement in Icelandic school children. Health Education Research, 2007, 22(1).

5. Tremblay MS, Imman JW, Willms JD. The relationship between physical activity, self-esteem, and academic achievement in 12-year-old children. Pediatric Exercise Science 2000;12:312323.

6. Taylor CB, Sallis JF, Needle R. The relation of physical activity and exercise to mental health. Public Health Rep 1986;100(2):195-202.

7. Martinsen EW, Hoffart A, Solberg O. Aerobic and nonaerobic forms of exercise in the treatment of anxiety disorders. Stress Med 1989;5:115-20.

8. Bahrke MS, Morgan WP. Anxiety reduction following exercise and meditation. Cogn Ther Res 1978;2(4):32333.

9. Lobitz WC, Brammell HL, Stoll S et al. Physical exercise and anxiety management training for cardiac stress management in a nonpatient population. J Card Rehabil 1983;3:683-8.

10. Yonkers KA, Zlotnick C, Allsworth J et al. Is the course of panic disorder the same in women and men? Am J Psychiatry PubMed 1998;155(5):596-602. 